\title{
7-deacetylgedunin suppresses inflammatory responses through activation of Keap1/Nrf2/HO-1 signaling
}

\author{
Jian-Yu Chen ${ }^{1}$, Guo-Yuan Zhu ${ }^{1}$, Xiao-Hui Su${ }^{1}$, Rui Wang ${ }^{1}$, Juan Liu ${ }^{1}$, Kangsheng \\ Liao $^{1}$, Rutong Ren ${ }^{1}$, Ting Li $^{1}$ and Liang Liu ${ }^{1}$ \\ ${ }^{1}$ State Key Laboratory of Quality Research in Chinese Medicine, Macau Institute for Applied Research in Medicine and Health, \\ Macau University of Science and Technology, Macau, China
}

Correspondence to: Ting Li, email: tli@must.edu.mo Liang Liu, email: Iliu@must.edu.mo

Keywords: 7-deacetylgedunin, anti-inflammation, Keap1, Nrf2, HO-1

Received: April 12, $2017 \quad$ Accepted: June 11, $2017 \quad$ Published: July 05, 2017

Copyright: Chen et al. This is an open-access article distributed under the terms of the Creative Commons Attribution License 3.0 (CC BY 3.0), which permits unrestricted use, distribution, and reproduction in any medium, provided the original author and source are credited.

\section{ABSTRACT}

Macrophages play a critical role in a variety of inflammatory diseases. Activation of Keap1/Nrf2/HO-1 signaling results in inactivation of macrophages and amelioration of inflammatory and autoimmune conditions. Hence, discovery for the activators of Keap1/Nrf2/HO-1 signaling has become a promising strategy for treatment inflammatory diseases. In the current study, the anti-inflammatory potential of 7-deacetylgedunin (7-DGD), a limonin chemical isolated from the fruits of Toona sinensis (A. Juss.) Roem, was intensively examined in vivo and in vitro for the first time. Results showed that 7-DGD alleviated mice mortality induced by LPS. Mechanistic study showed that 7-DGD suppressed macrophage proliferation via induction of cell arrest at the G0/G1 phase. Furthermore, 7-DGD inhibited iNOS expression, which is correlated with the increases of NQO1, HO-1 and UGT1A1 mRNA expression as well as HO-1 protein expression level in the cells. More importantly, 7-DGD markedly decreased Keap1 expression, promoted p62 expression, and facilitated Nrf2 translocation and localization in the nucleus of macrophages, and in turn up-regulates these anti-oxidant enzymes expression, eventually mediated anti-inflammatory effect. Collectively, 7-DGD suppresses inflammation in vivo and in vitro, indicating that the compound is valuable for further investigation as an antiinflammatory agent in future.

\section{INTRODUCTION}

Inflammation is one of the major pathogenic events in a variety of diseases in which macrophages play crucial roles [1]. When macrophages are stimulated by inflammatory stimuli, they become activated and secrete pro-inflammatory mediators, growth factors, bioactive lipids, hydrolytic enzymes, reactive oxygen intermediates, and nitric oxide [2] and promote the synthesis of prostaglandins [3]. Consequently, inflammatory responses and even disease conditions are induced. Moreover, inducible NOS (iNOS) and cyclooxygenase-2 (COX-2) are two key factors in the processes of inflammation and disease progression; in the quiescent stage of macrophages, both remain unexpressed. In contrast, when quiescent cells are stimulated by interferon gamma (IFN- $\gamma$ ), lipopolysaccharides (LPS) and other pro-inflammatory cytokines [4], iNOS and COX-2 are overexpressed, and the increased expression of iNOS and COX-2 causes the release of $\mathrm{NO}$ and $\mathrm{PGE}_{2}$, inducing inflammatory reactions [5].

Oxidative stress plays important roles in both inflammatory and anti-inflammatory responses by activating various transcription factors such as NF- $\mathrm{kB}, \mathrm{AP}-1, \mathrm{p} 53$, HIF-1 $\alpha$, PPAR- $\gamma, \beta$-catenin/Wnt, and NF-E2-related factor 2 (Nrf2), which regulate more than 500 different genes of growth factors, inflammatory cytokines, chemokines, cell cycle regulatory molecules, and anti-inflammatory molecules [6]. Heme oxygenase-1(HO-1), a stress-inducible protein in the Keap1/Nrf2/HO-1 pathway, is induced by various oxidative and inflammatory signals, subsequently inducing anti-inflammatory activity. Therefore, HO-1 functions as 
an adaptive cellular response against inflammation and oxidative injury and it is regulated by Nrf2 [7]. Under nonstressed conditions, Nrf2 is constantly ubiquitinated by the Cul3-Keap1 ubiquitin E3 ligase complex and rapidly degraded [7]. When the cell experiences conditions of stress or in the presence of electrophiles, the cysteine residues in Keap1 are modified, resulting in Nrf2 release. Free Nrf2 accumulates in the cytosol, and then translocates to the nucleus where it binds to the ARE [8], activating the transcription of chemopreventive genes, including UDPglucuronosyltransferases (UGTs), detoxifying enzymes $\mathrm{NAD}(\mathrm{P}) \mathrm{H}$, dehydrogenases (NQOs), and HO-1 [9, 10]. It has been well-known that phosphorylation of $\mathrm{Nrf} 2$ at tyrosine 568 is attributed to the nuclear export of Nrf2. Furthermore, up-regulation of p62 can bind to Keap1 thereby disrupting the interaction between Nrf2 and Keap1, leading to release of Nrf2 from Keap1, eventually, facilitating Nrf2 translocation from cytoplasm to nucleus [11, 12]. Collectively, Nrf2 signaling can not only manipulate redox signaling but also attenuate inflammation-associated pathogenesis in many diseased conditions including rheumatoid arthritis, asthma and atherosclerosis [13-15].

In the recent decades, increasing attention has been given to the study of Nrf2 signaling, especially in macrophages, for screening of active components from medicinal plants for anti-inflammation. For the first time, in 2011, it was reported that gedunin (GDN), an analog of 7-DGD, activated Nrf2 signaling based on an Neh2luciferase reporter assay [16]. Also, GDN was found to be an inhibitor of heat shock protein 90 (Hsp90) and an activator of the transcription factor heat shock factor 1 (hsf1) $[17,18]$. However, the anti-inflammatory effects of 7-DGD in vivo has not been studied till now. In the current work, we for the first time determined the antiinflammatory effect and elucidated underlying mechanism of 7-DGD in vivo and in vitro.

\section{RESULTS}

\section{7-DGD mediates the anti-inflammatory effect on LPS-induced septic shock in vivo without significant cytotoxicity on macrophages}

7-deacetylgedunin (7-DGD) (>98\% purity, verified by HPLC) was isolated from the fruits of Toona sinensis (A. Juss.) Roem. Its structure was elucidated on the basis of spectroscopic analysis (NMR data shown in Figure 1A and $1 \mathrm{~B})$. It was recently reported that gedunin, an analog of 7-DGD, has potential to inhibit the production of TNF- $\alpha$, IL-6 and NO [19]. We therefore determined whether 7-DGD could ameliorate the pathogenesis of LPS-induced septic shock in mice, although the anti-inflammatory effect of the compound has not been investigated in animal. In the experiment, C57BL/6 mice were intraperitoneally injected with $5 \mathrm{mg} / \mathrm{kg}$ 7-DGD once per day for consecutive two days, followed with the treatment of LPS. As shown in Figure 2A, the results showed that all of the mice- treated by LPS were died within $84 \mathrm{~h}$, and $40 \%$ mice administrated with 7-DGD were survived, showing that 7-DGD has anti-inflammatory function in vivo.

Activation of macrophages are heavily involved in the initiation and progression of inflammation [20]. Therefore, we further determined if the anti-inflammatory effect of 7-DGD resulted from the toxicity on macrophage. The results showed that $50 \mu \mathrm{M}$ 7-DGD suppressed cell viability by $67 \%$ compared to the vehicle-treated cells (Figure 2B), and the dead cells were clearly observed under the microscope. When the cells were treated with 7-DGD at $100 \mu \mathrm{M}$, the suppression reached $80 \%$, and the dead cells were more abundant (Figure 2E). However, treatment with $25 \mu \mathrm{M}$ 7-DGD did not induce visible cell death, although the number of the viable cells was less than non-treated cells, indicating that 7-DGD probably inhibited macrophage proliferation rather than killed the cells. We further examined if the inhibitory effect of 7-DGD on macrophage proliferation attributed to the cell cycle arrest. It was found that 7-DGD at $10 \mu \mathrm{M}$ and $25 \mu \mathrm{M}$ concentrations significantly induced the cell cycle arrest of RAW264.9 cells at G0/G1 phase (Figure 2C-2D), suggesting that anti-inflammatory effect of 7-DGD may result from inhibition on the production of inflammatory mediators rather than cytotoxicity.

\section{7-DGD significantly inhibits mRNA and protein expression of iNOS, and mRNA expression of IL- $1 \beta$ and TNF- $\alpha$ in macrophages}

iNOS and COX-2 play pivotal roles in oxidative and inflammatory events [20]. We examined whether 7-DGD could influence iNOS and COX-2 expression. The results showed that 7-DGD could almost completely attenuate iNOS protein expression at $10 \mu \mathrm{M}$ (Figure 3A-3B), while $\mathrm{COX}-2$ protein expression remained unchanged up to $25 \mu \mathrm{M}$ concentration (Figure 3C-3D). Therefore, we further determined whether the inhibitory effect of 7-DGD on iNOS expression resulted from transcriptional suppression. In coincided with the results, 7-DGD significantly inhibited the mRNA expression level of iNOS (Figure 3E). It is well known that the cytokines, including TNF- $\alpha$ and IL-1 $\beta$, play a significant role in inflammatory activities. Accordingly, the effects of 7-DGD on the mRNA expression of TNF- $\alpha$ and IL-1 $\beta$ were determined, and the results demonstrated that 7-DGD could significantly inhibit IL- $1 \beta$ and TNF- $\alpha$ mRNA expression (Figure $3 \mathrm{~F}-3 \mathrm{G}$ ), suggesting that 7-DGD has anti-inflammatory potential in macrophages.

\section{7-DGD enhances NQO1, HO-1 and UGT1A1 mRNA expression, and $\mathrm{HO}-1$ protein expression level with accumulation of $\mathrm{Nrf} 2$ in macrophages}

Decreased HO-1 and other anti-oxidant enzymes can induce over-production of iNOS and COX-2, and 
up-regulation of HO-1 has been reported to exert antiinflammation as well as anti-oxidant effects [21]. Therefore, we further examined whether or not the inhibitory effect of 7-DGD is resulted from up-regulation of NQO1, HO-1 and UGT1A1. As anticipated, the results showed mRNA expression of NQO1, HO-1, and UGT1A1 was increased by 7-DGD, especially at $25 \mu \mathrm{M}$ (Figure 4A-4C).
We further verified the effect of 7-DGD on HO-1 protein expression in RAW264.7 with LPS stimulation, and the results revealed that 7-DGD could strongly facilitate HO-1 expression in a dose-dependent manner in RAW 264.7 with LPS stimulation (Figure 4D-4E), indicating that suppression of macrophage activation induced by 7 -DGD relies on the up-regulation of the

A

1 H NMR

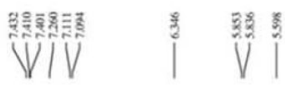<smiles>CC1(C)C(=O)C=C[C@@]2(C)C1C[C@@H](O)[C@@]1(C)C2CC[C@]2(C)[C@@H](c3ccoc3)OC(=O)[C@@H]3O[C@@]321</smiles>

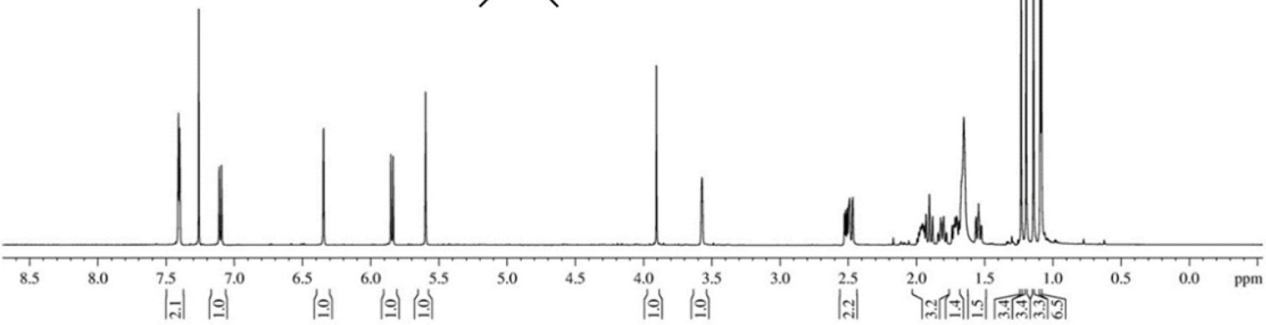

B

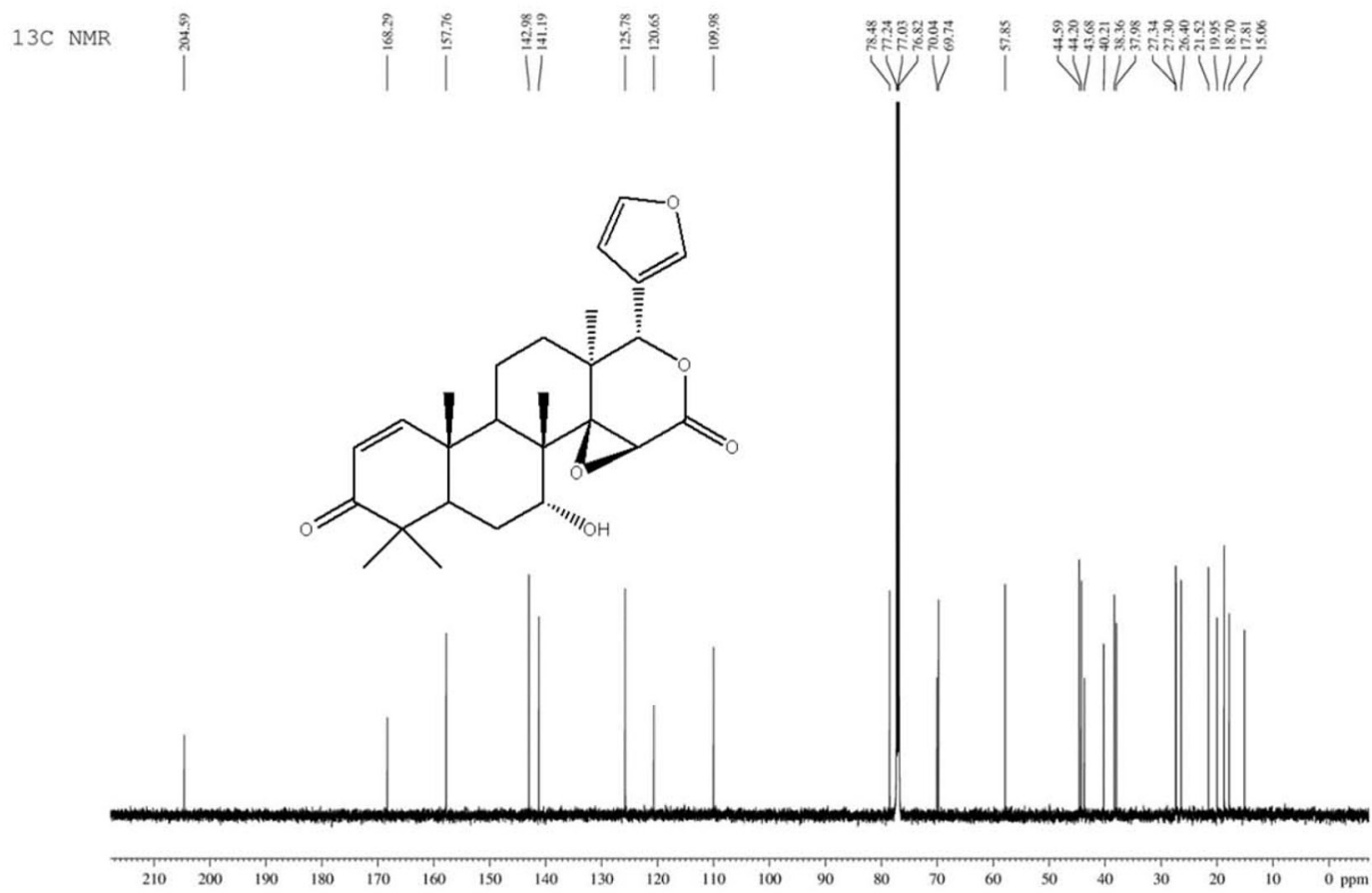

Figure 1: The structure of 7-deacetylgedunin (7-DGD). ${ }^{1} \mathrm{H}$ NMR spectrum of 7-DGD (A). ${ }^{13} \mathrm{C}$ NMR spectrum of 7-DGD (B). 
A

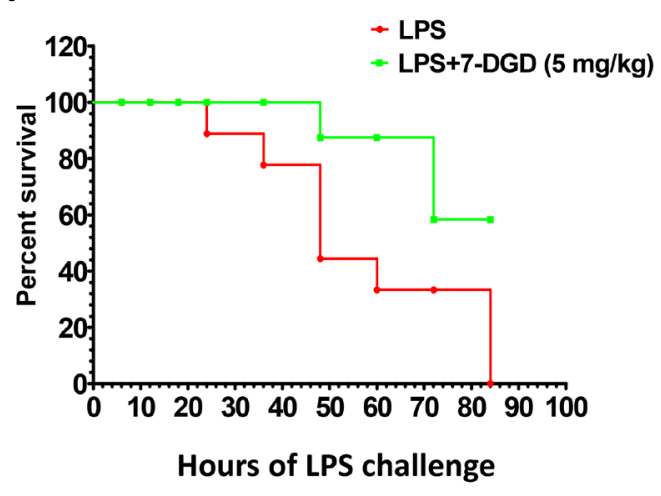

B

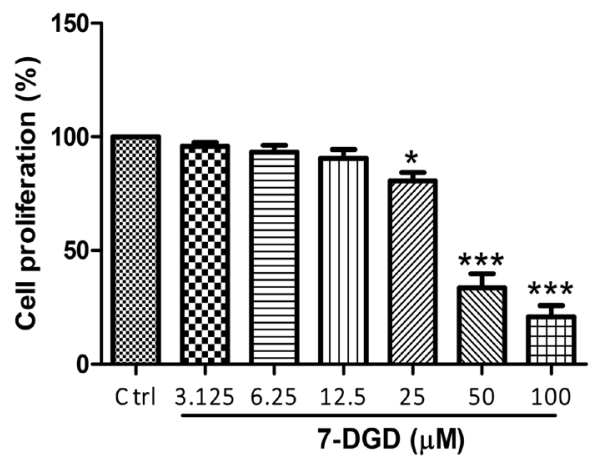

C

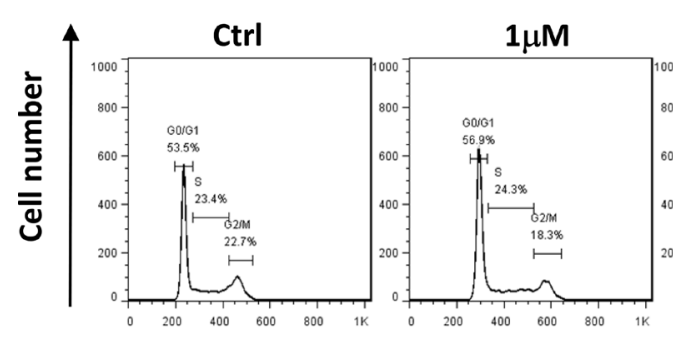

$5 \mu \mathrm{M}$

$10 \mu \mathrm{M}$

$25 \mu \mathrm{M}$
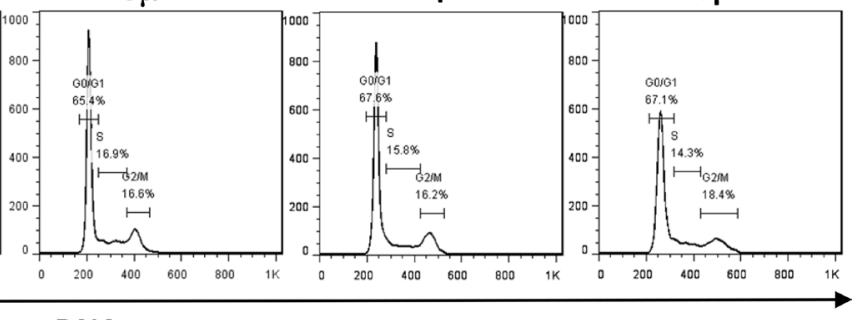

DNA content

D

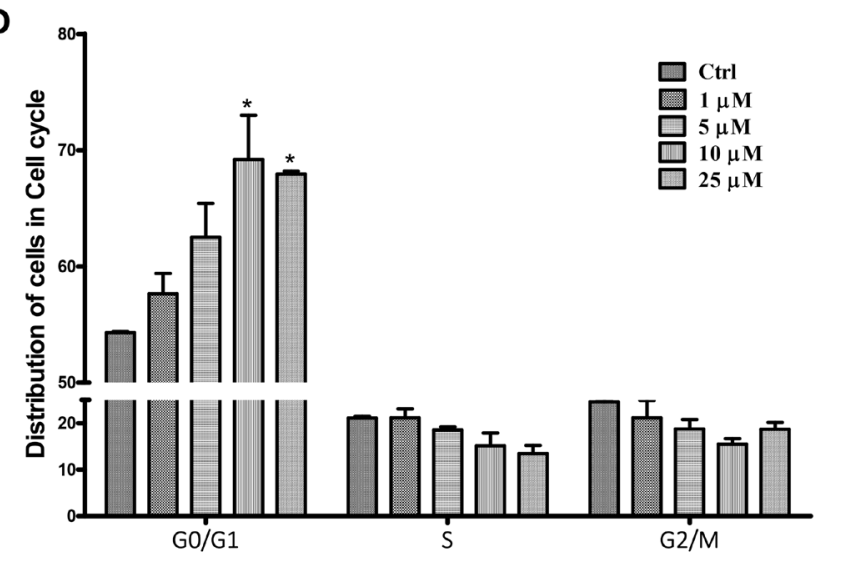

E

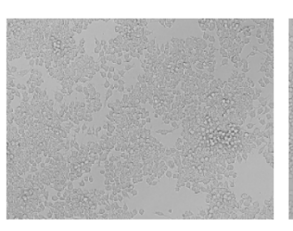

Ctrl

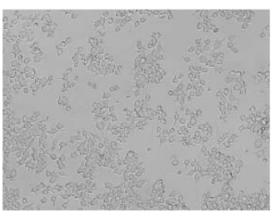

$25 \mu \mathrm{M}$

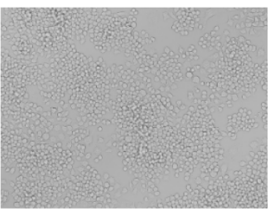

$1 \mu \mathrm{M}$

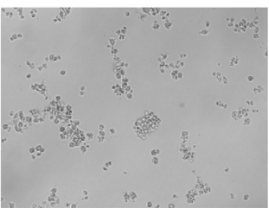

$50 \mu \mathrm{M}$

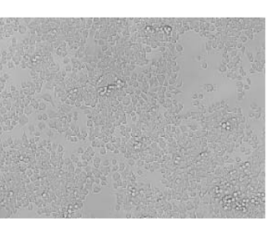

$5 \mu \mathrm{M}$

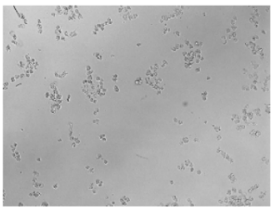

$100 \mu \mathrm{M}$

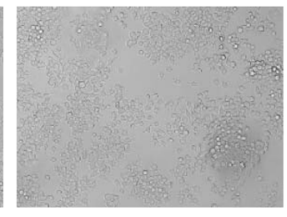

$10 \mu \mathrm{M}$

Figure 2: 7-DGD alleviated the mortality of LPS-induced endotoxin shock in mice. $8-11$ week-old female C57BL/6 mice were injected intraperitoneally with LPS $(20 \mathrm{mg} / \mathrm{kg})$ in the presence of 7-DGD $(5 \mathrm{mg} / \mathrm{kg}, n=7)$ or vehicle $(n=8)(\mathbf{A})$. 7-DGD inhibited RAW 264.7 cells proliferation (B and E). 7-DGD induced RAW264.7 cell cycle arrest (C-D). Data were obtained from three independent experiments and the results were expressed as mean \pm SEM. ${ }^{*} p<0.05,{ }^{* *} p<0.01,{ }^{* * *} p<0.001$ vs control. 
A

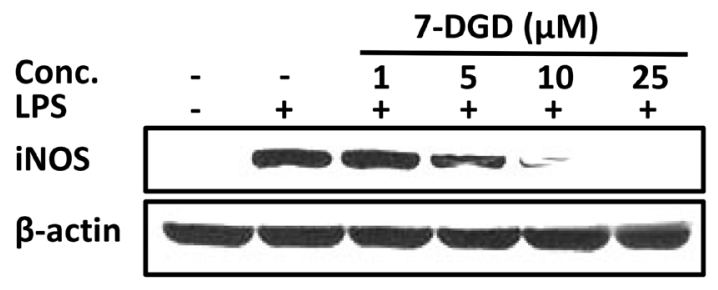

C
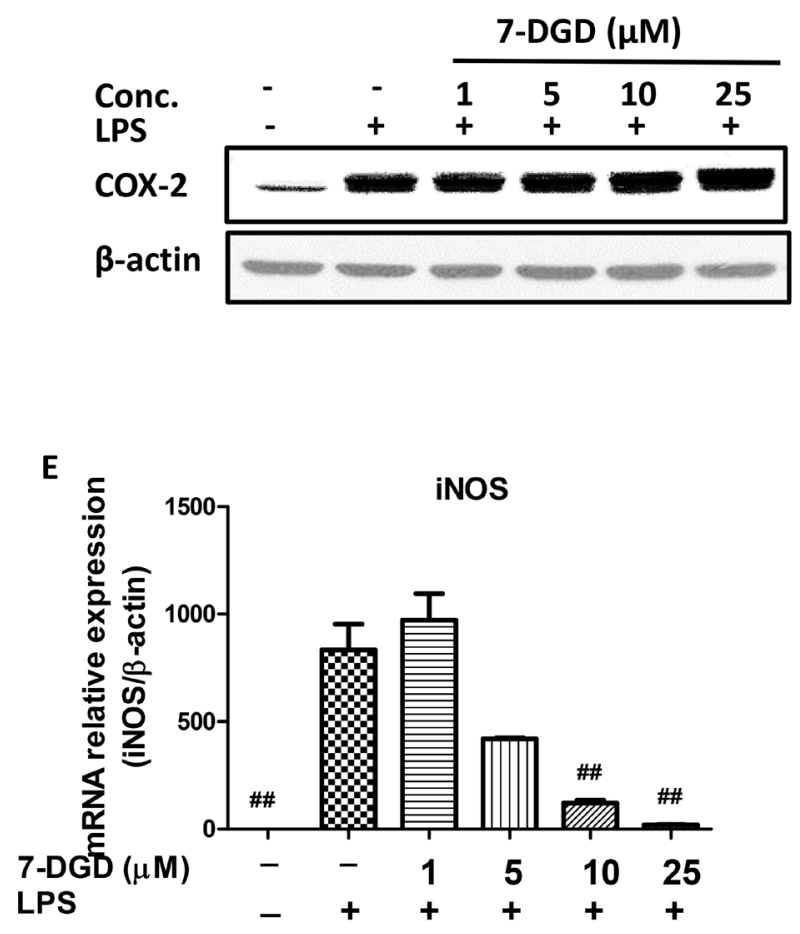

G

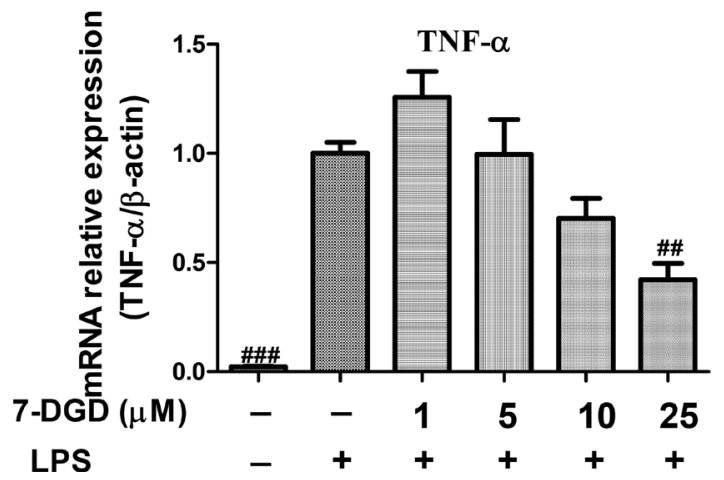

B

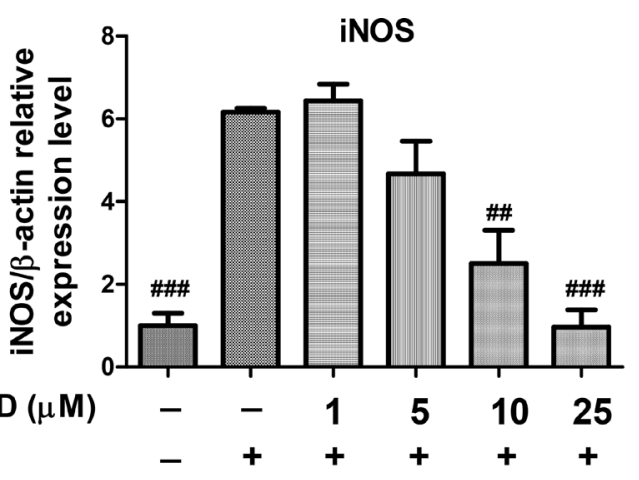

D
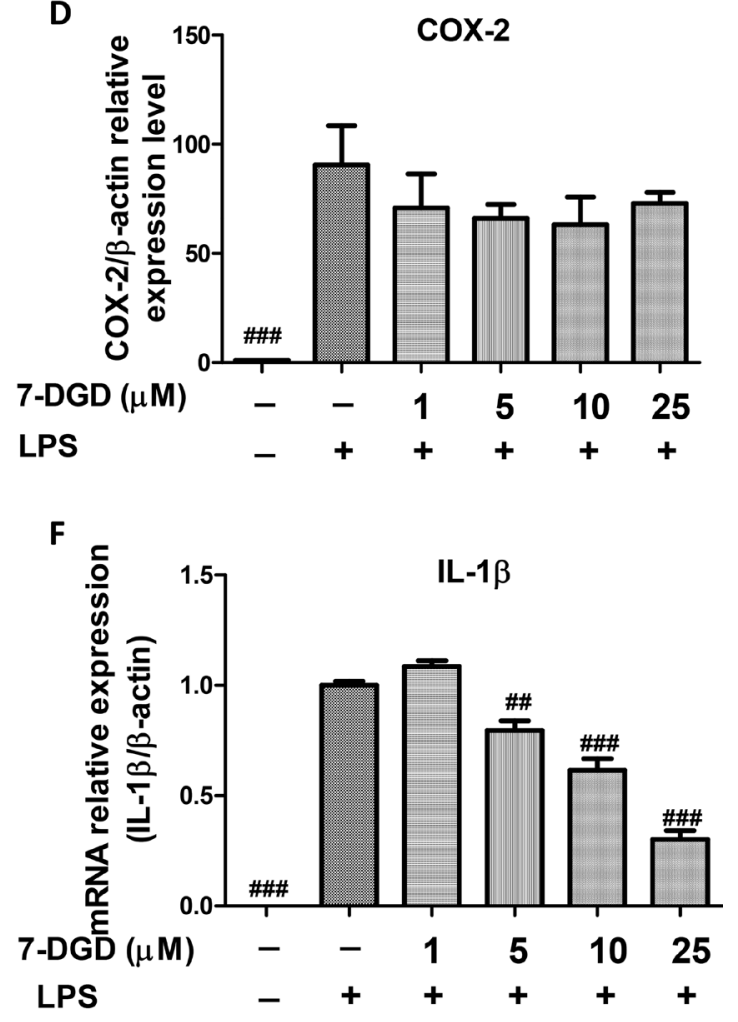

Figure 3: 7-DGD inhibited mRNA and protein expression of iNOS, and mRNA expression of IL-1 $\beta$ and TNF- $\alpha$ in RAW 264.7 cells induced by LPS. The effect of 7-DGD on iNOS protein expression (A-B). The effect of 7-DGD on COX-2 protein expression (C-D). The effect of 7-DGD on iNOS mRNA expression (E). The effect of 7-DGD on mRNA expression of IL-1 $\beta$ and TNF- $\alpha$ $(\mathbf{F}-\mathbf{G})$. Data were obtained from three independent experiments and the results were expressed as mean \pm SEM, ${ }^{\#} p<0.05,{ }^{\prime \prime} p<0.01$, $\ldots$ \# $p .001$ vs LPS group. 
anti-oxidative enzymes expression. It was reported that the anti-oxidative enzymes including NQO1, HO-1 and UGT1A1 are regulated by $\operatorname{Nrf} 2[13,15]$. Interestingly, we found that 7-DGD induced accumulation of Nrf2 in the cells (Figure 4F-4G) without affecting mRNA expression level of Nrf2 (Figure 4H), indicating that 7-DGD probably prevented Nrf2 ubiquitination rather than overexpression.

\section{7-DGD promotes Nrf2 localization in the nucleus of macrophages}

As 7-DGD could obviously facilitate $\mathrm{Nrf} 2$ accumulation in cytoplasm, we further determined whether the compound could promote Nrf2 nucleus translocation. Additionally, it is well known that Nrf2 dimerizes with small Maf proteins and binds to ARE to activate these anti-oxidant enzymes transcription when it translocates to cell nucleus. Before determining the effect of 7-DGD on Nrf2 nucleus translocation, we examined the effect of 7-DGD on ARE luciferase activity on HepG2-C8 cells, the stably transfected cells with an ARE-luciferase reporter vector. As shown in Figure 5A, the reference compound, isoliquiritigenin (ILG), could significantly increase ARE luciferase activity, which is coincided with previous study [22]. As expectation, 7-DGD up-regulated the luciferase activity of ARE (Figure 5A). Furthermore, it was reported that the function of the activated Nrf2 relies on its translocation from the cytoplasma into the nucleus $[9,15]$, indicating that 7-DGD probably has the ability to promote Nrf2 nucleus translocation. So, it is valuable to examine the effect of 7-DGD on Nrf2 translocation into the nucleus of macrophages by western blotting and immunocytochemistry assays. As shown in Figure 5B-5D, 7-DGD could obviously increase Nrf2 translocation from cytoplasm to the nucleus of RAW264.7 cells. In coincided with the results, the immunocytochemistry analysis showed that 7-DGD intensively induced the Nrf2 localization in the nucleus of 7-DGD-treated cells at $10 \mu \mathrm{M}$ and $25 \mu \mathrm{M}$ (Figure 5E). These findings suggested that 7-DGD can promote Nrf2 localization in the nucleus of macrophages and in turn up-regulate anti-oxidative gene transcription to inhibit inflammation.

\section{7-DGD activates Nrf2 signaling by regulation of Keap1 and p62 expression}

Nrf2 is normally sequestered in the cytoplasm by a protein known as Keap1. When Keap1 is challenged, blockage of Nrf2 ubiquitylation is induced and Nrf2 translocation from the cytoplasm to the nucleus is increased. Considering the crucial role of Keap1 in Nrf2, the effect of 7-DGD on Keap1 expression was determined. As shown in Figure 6A-6D, 7-DGD could intensively inhibit Keap1 expression in RAW264.7 cells with or without LPS stimulation, indicating that 7-DGD induced Nrf2 accumulation probably through suppressing Keap1 expression.
Recently, p62 was reported to activate Nrf2 by inactivation of Keap1 through interaction between the Nrf2-binding site on Keap1 at the Keap1-DC domain and p62-KIR [12]. We further examined the effect of 7-DGD on p62 expression and found that 7-DGD significantly promoted p62 expression in RAW264.7 macrophages with or without LPS stimulation in a dose-dependent manner (Figure 6E-6H), suggesting that 7-DGD facilitated Nrf2 accumulation and nucleus translocation due to upregulation of p62 and inhibition of Keap1.

\section{DISCUSSION AND CONCLUSIONS}

In the recent decades, an increasing number of reports have indicated that inflammatory responses are a common pathogenesis of a variety of diseases [23], in which macrophages function as critical participants in inflammatory and autoimmune processes. A number of pro-inflammatory proteins and enzymes, such as iNOS, COX-2 and Keap1/Nrf2/HO-1 signaling, in macrophages have been found to influence and attenuate inflammationassociated pathogenesis of a variety of diseases [14].

The anti-inflammatory effect of 7-DGD, a limonoid isolated from $T$. sinensis, has not been investigated yet. In the current study, we for the first time demonstrated that 7-DGD alleviated mice mortality induced by LPS, indicating that the compound has anti-inflammatory potential in vivo. The macrophage cell line, RAW 264.7, was employed to explore the underlying mechanism of 7-DGD. The results of proliferation and cell cycle assay revealed that the anti-inflammatory effect of the compound cannot be attributed to cytotoxicity in macrophages.

It is well-known that iNOS is one of the key inflammatory mediators associated with pathogenesis and pathological changes in many diseased conditions [24, 25], In the current work, we found that 7-DGD possesses the promising function of inhibiting iNOS expression in RAW264.7 macrophages stimulated by LPS for $24 \mathrm{~h}$, while it has no influence on COX-2 expression, indicating that 7-DGD has selective inhibitory effect on iNOS expression. In addition, the inhibitory effect of 7-DGD on TNF- $\alpha$ and IL- $1 \beta$ showed that the compound has the antiinflammatory effect in macrophages.

Although the effect of 7-DGD on Nrf2 signaling has not been studied, GDN, the 7-DGD analog, has been served as an Nrf2 activator in the Neh2-luciferase reporter assay [16]. It was reported that disruption or loss of Nrf2 signaling causes enhanced susceptibility not only to oxidative and electrophilic stresses but also to inflammatory tissue injuries [26]. Furthermore, Nrf2 knockout mice exhibited significantly increased iNOS expression compared with their wild-type counterparts $[27,28]$, implying that activation of Nrf2 probably contributed the anti-inflammatory effect of 7-DGD. Therefore, we conducted intensive studies on 7-DGD with respect to the correlation between iNOS expression 
A
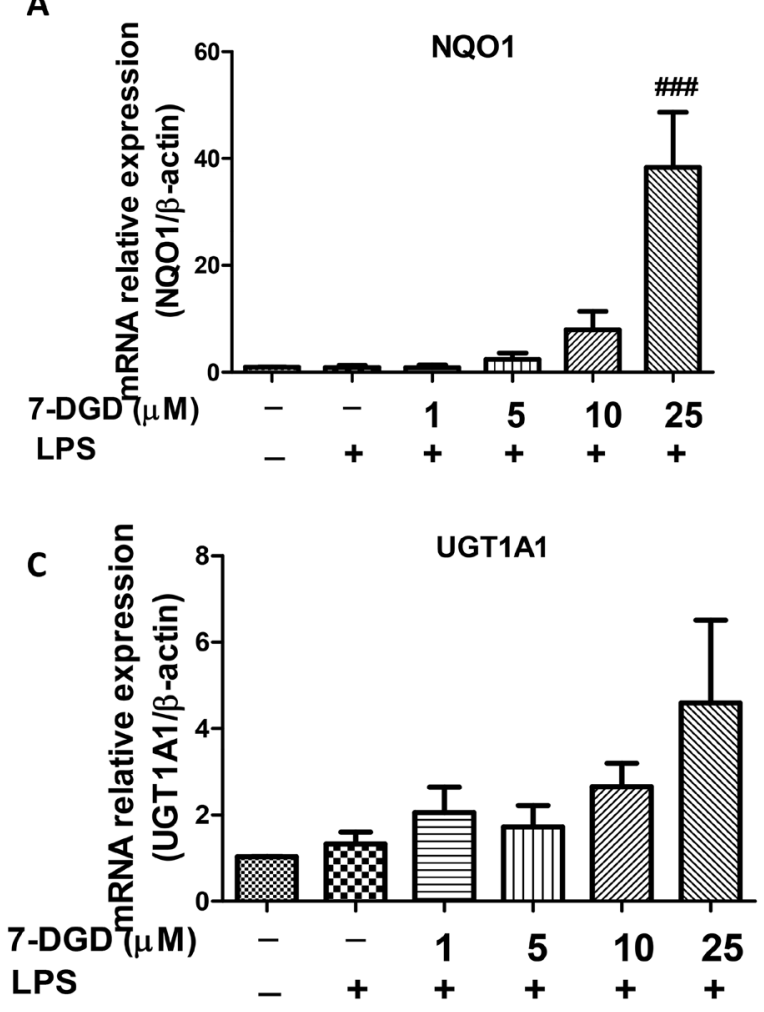

E

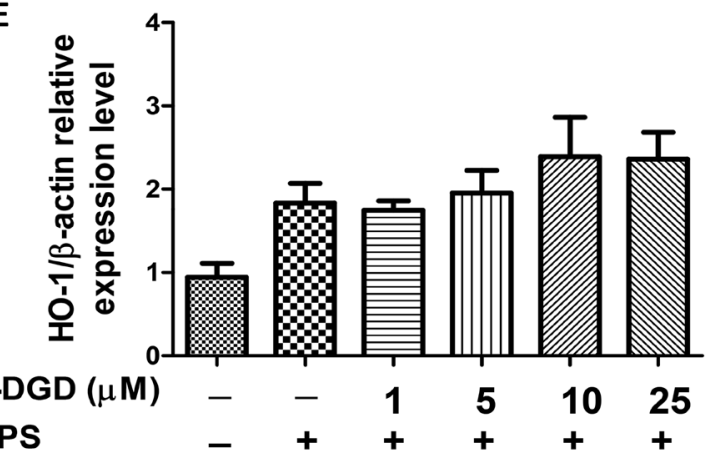

G

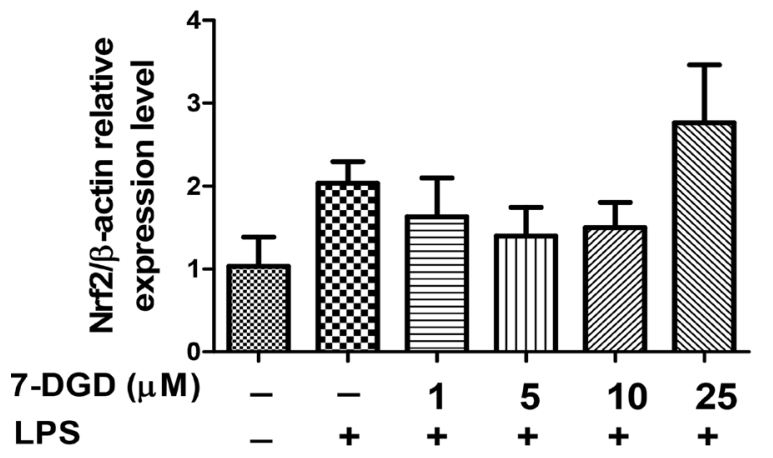

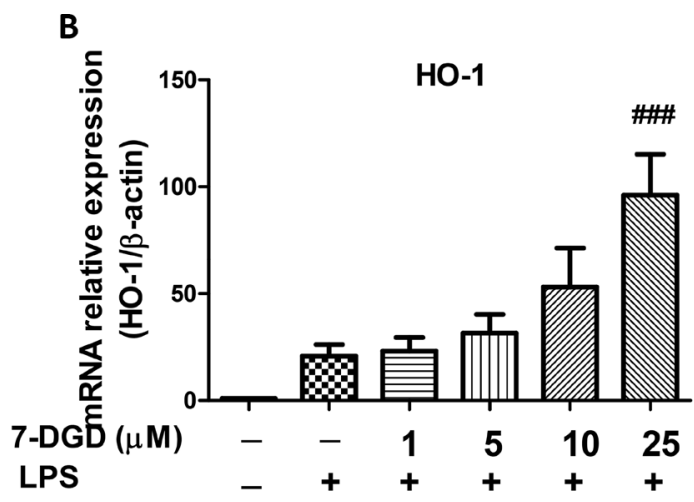

D

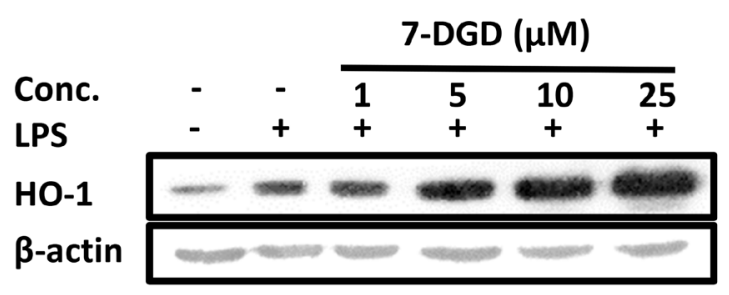

$\mathbf{F}$

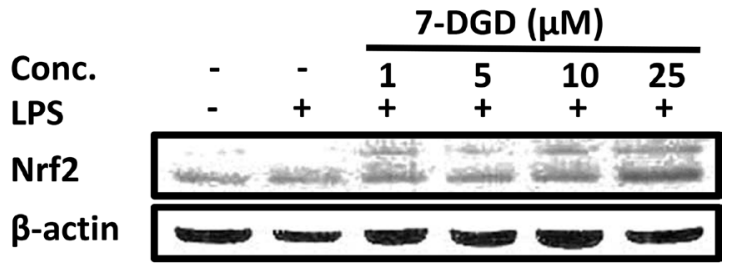

H

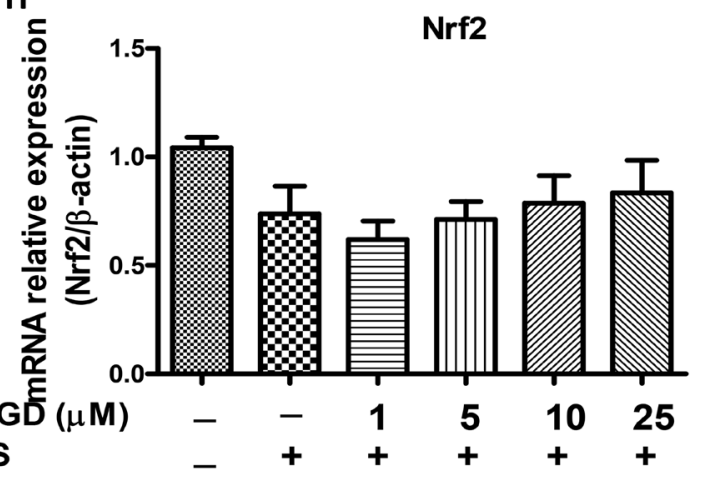

Figure 4: 7-DGD up-regulated anti-oxidant enzymes mRNA and protein expression, as well as Nrf2 accumulation in RAW264.7 cells induced by LPS. The effect of 7-DGD on NQO1, HO-1 and UGT1A1 mRNA expression (A-C). The effect of 7-DGD on HO-1 protein expression (D-E). The effect of 7-DGD on Nrf-2 protein expression (F-G). The effect of 7-DGD on Nrf-2 mRNA expression $(\mathbf{H})$. Data were obtained from three independent experiments and the results were expressed as mean $\pm \operatorname{SEM} .{ }^{*} p<0.05$, ${ }^{\#} p<0.01,{ }^{\# \#} p<0.001$ vs LPS group. 
A

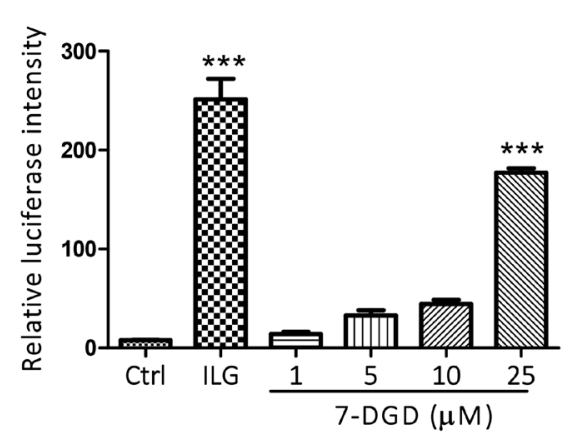

C

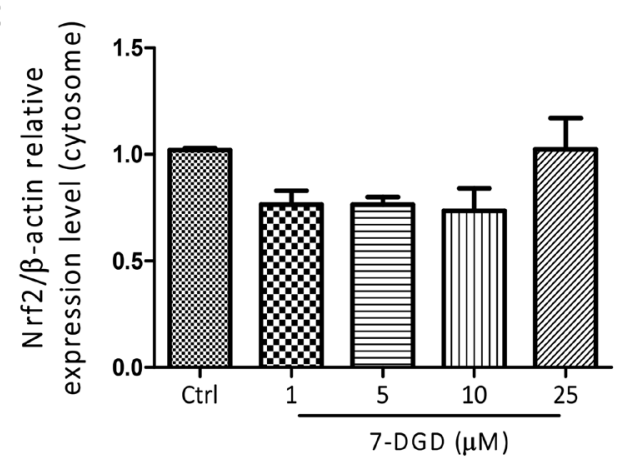

E
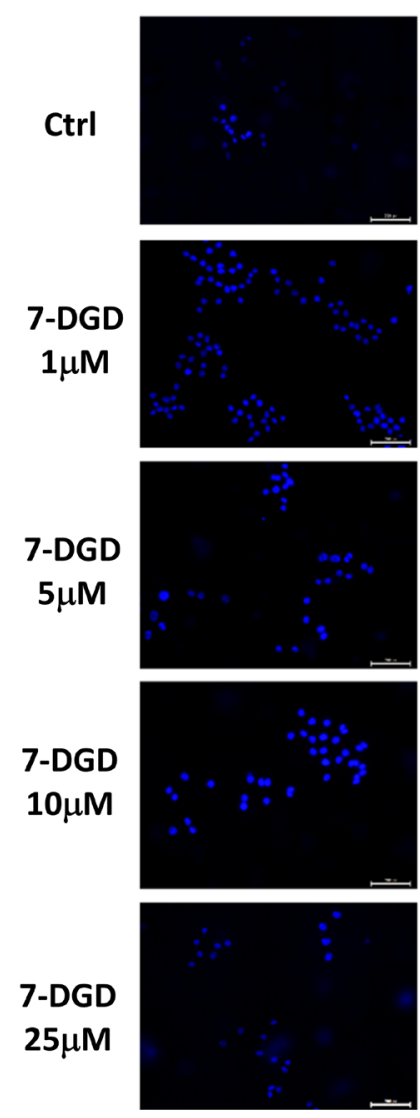

B
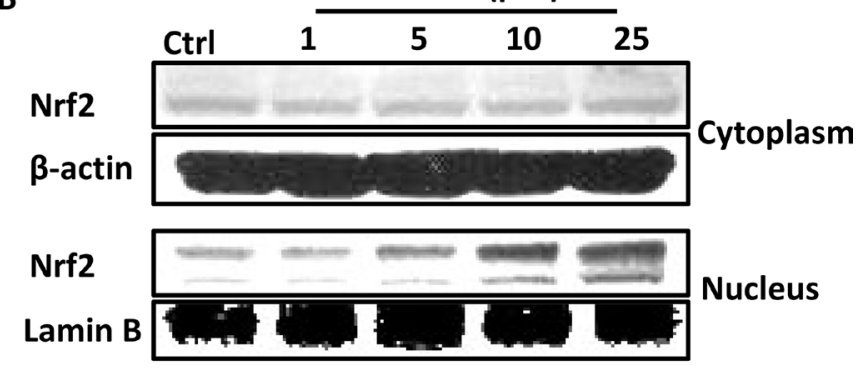

D

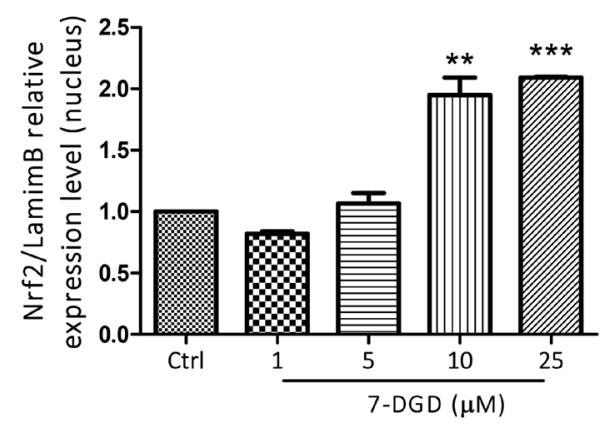

Nrf-2
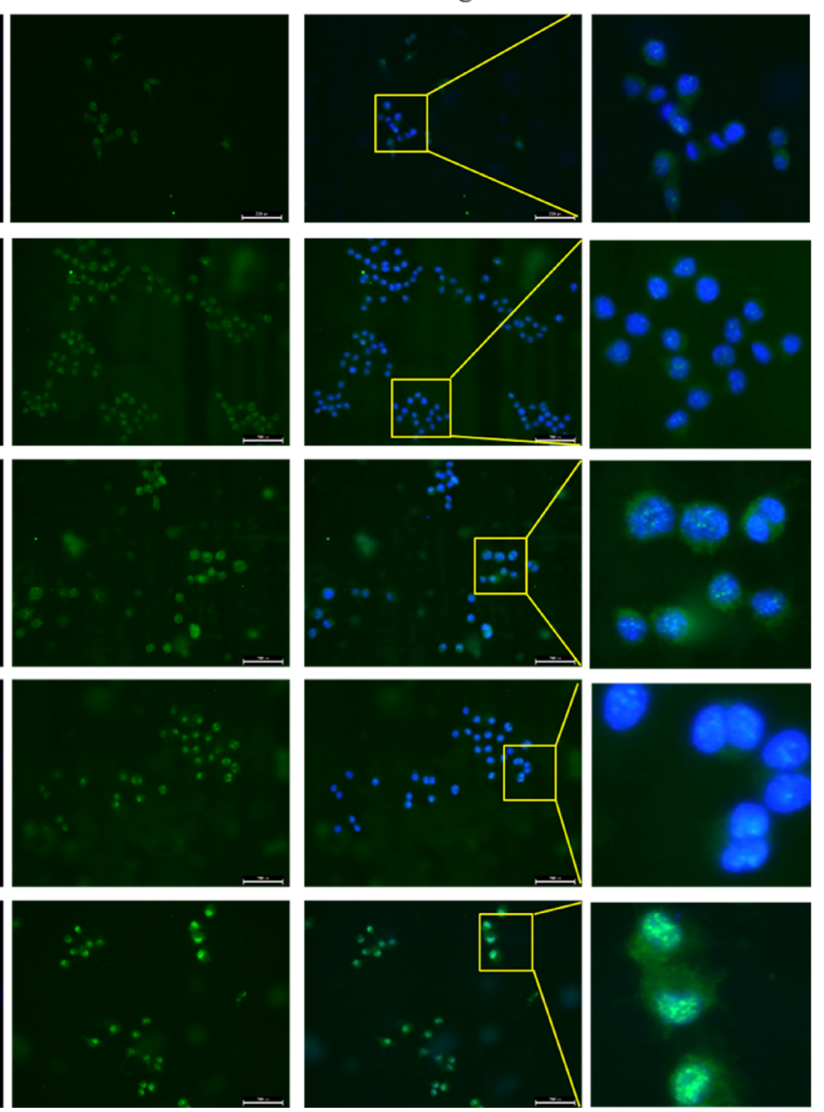

Figure 5: 7-DGD facilitated Nrf2 nucleus translocation in RAW264.7 cells. The effect of 7-DGD on ARE luciferase activity (A). The effect of 7-DGD on Nrf2 nucleus translocation determined by western blotting (B-D) and immunofluorescence (E) in RAW264.7 cells. Data were obtained from two or three independent experiments and the results were expressed as mean \pm SEM. ${ }^{*} p<0.05,{ }^{* *} p<0.01$, ${ }^{* * *} p<0.001 v s$ control. 
A

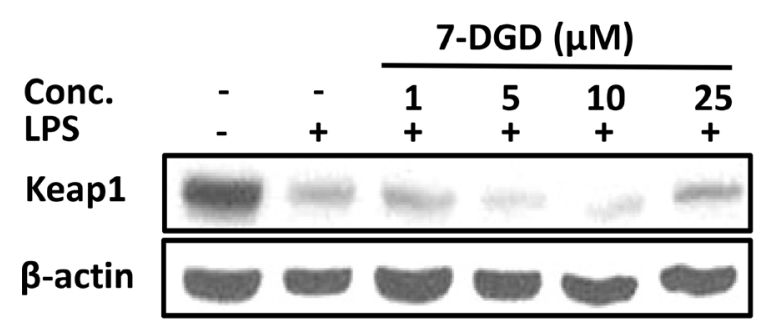

C

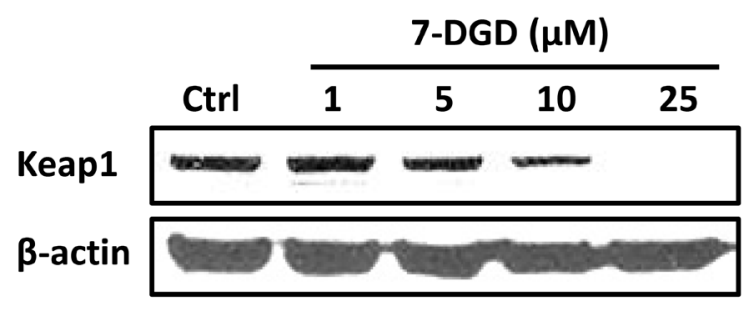

$\mathbf{E}$

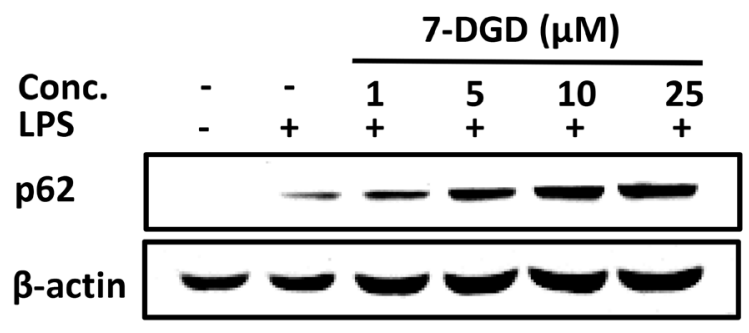

G

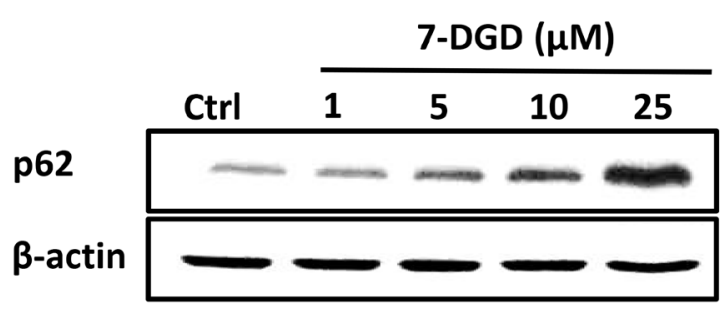

B

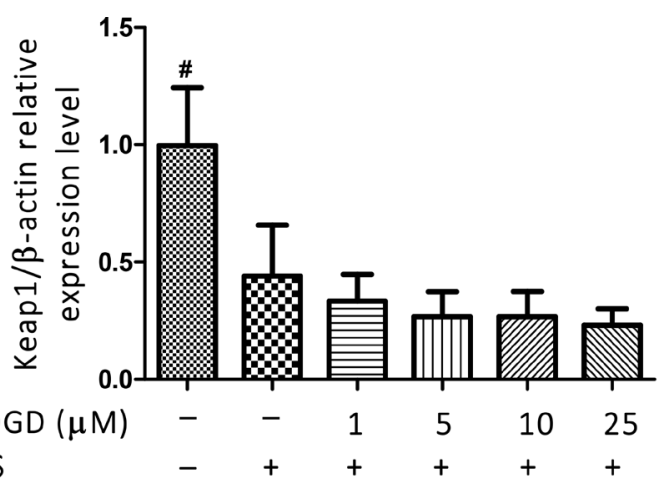

D
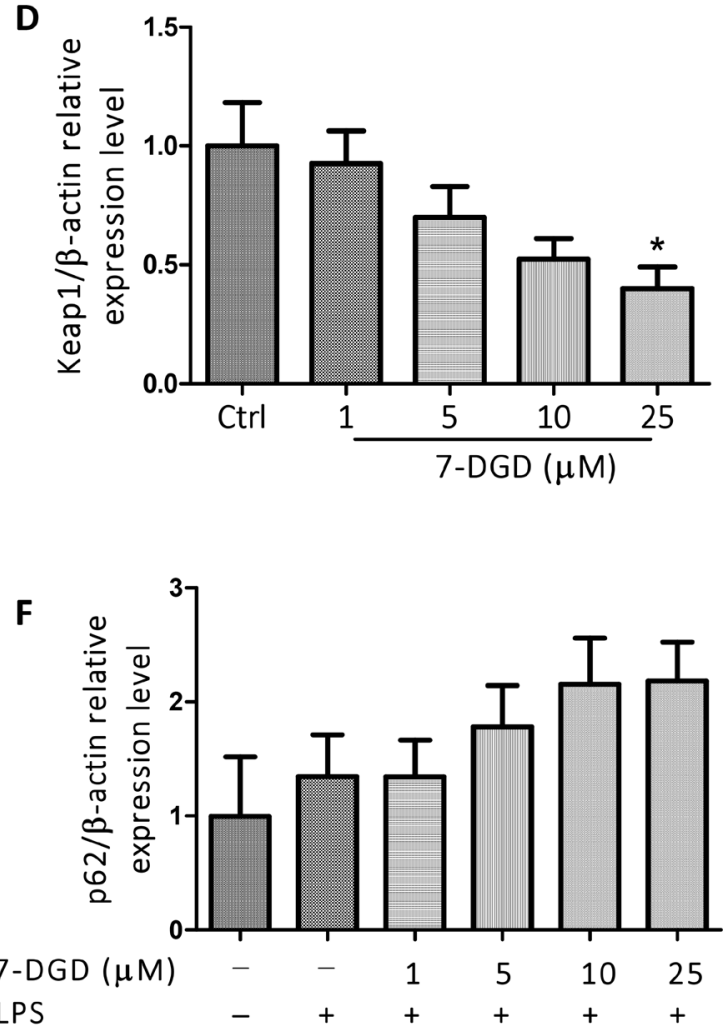

H

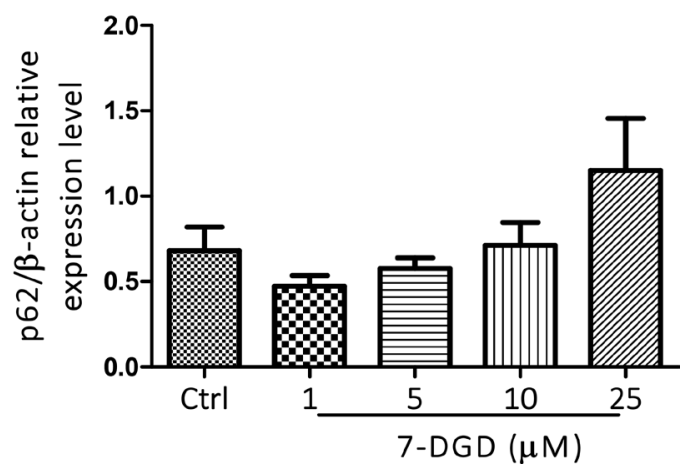

Figure 6: 7-DGD induced Keap1 degradation and promoted p62 expression. The effect of 7-DGD on Keap-1 expression in RAW264.7 cells with (A-B) or without (C-D) LPS stimulation. The effect of 7-DGD on p62 expression in RAW264.7 cells with (E-F) or without $(\mathbf{G}-\mathbf{H})$ LPS stimulation. Data were obtained from three independent experiments and the results were expressed as mean \pm SEM. ${ }^{*} p<0.05,{ }^{* *} p<0.01,{ }^{* * *} p<0.001$ vs control, ${ }^{\#} p<0.05,{ }^{\#} p<0.01,{ }^{\# \#} p<0.001$ vs LPS group. 
and Keap1/Nrf2/HO-1 signaling. When Nrf2 is activated, it binds to ARE located in the promoter region of genes encoding HO-1, NOQ1 and UGT1A1. Our results clearly demonstrated that 7-DGD significantly enhanced HO-1, NOQ1 and UGT1A1 mRNA expression. Among these enzymes regulated by Nrf2, HO-1 has pronounced antioxidative and anti-inflammatory properties, and it is a crucial modulator to regulate the innate immunity and inflammation [29]. In the study, we found 7-DGD obviously up-regulated HO-1 protein expression level.

Under the basal resting condition, Nrf2 is sequestered in the cytoplasm by Keap1, which functions as a negative modulator of $\mathrm{Nrf} 2$ by promoting ubiquitination and proteasomal degradation of Nrf2. In the study, 7-DGD significantly inhibited Keap1 expression and enhanced Nrf2 expression in cytoplasm. Interestingly, 7-DGD has not obvious effect on Nrf2 mRNA expression level, suggesting that the compound cannot affect Nrf2 transcription. Therefore, Nrf2 accumulation in cytoplasm induced by 7-DGD was attributed to inhibition on Keap1.

It has been well-known that p62 functions as a selective autophagy receptor for degradation of ubiquitinated substrates. It was reported that mTORC phosphorylates S349 of p62 and increases binding affinity of p62 to Keap1, resulting in the escape of Nrf2 from the Keap1 interaction. Free Nrf2 enables activation of various target genes, including p62, which creates a positive feedback loop in the p62-Keap1-Nrf2 axis [12, 30]. In our current study, 7-DGD increased Nrf2 nucleus localization and in turn up-regulated p62 mRNA and protein expression. On the other hand, TRIM21, an ubiquitin E3 ligase negatively regulates the p62-Keap1-Nrf2 axis by undoing p62 oligomerization. According to the literature reports and our results, we speculated that 7-DGD probably targets on mTOR complex 1 (mTORC1) or TRIM2, and then activates p62-Keap1-Nrf2 axis to mediate anti-inflammatory effect.

Taken together, for the first time, we reported the anti-inflammatory effect of 7-DGD in vivo and in vitro. Mechanistic study explored that 7-DGD suppressed the macrophages proliferation through arresting cell cycle at the G0/G1 phase, and inhibited iNOS expression via activation Nrf2/ARE/HO-1 signaling. The effect of 7-DGD on Nrf2 accumulation and nucleus translocation resulted from inhibition of Keap-1 expression and up-regulation of p62 expression, and then enhanced HO-1, NOQ1 and UGT1A1 mRNA expression and HO-1 protein expression level, finally mediated anti-inflammatory effect. In conclusion, 7-DGD suppressed inflammation in vivo and in vitro via activation of Keap1/Nrf2/HO-1 signaling. In future, 7-DGD is valuable for further investigation as an anti-inflammatory agent.

\section{MATERIALS AND METHODS}

\section{Cells and reagents}

RAW264.7 cells were purchased from American Type Culture Collection (ATCC, Manassas, VA,
USA) and were cultured in DMEM (Gibco, Paisley, UK) with $10 \%(\mathrm{v} / \mathrm{v})$ fetal bovine serum (FBS; Gibco, Paisley, UK), penicillin (100 units/ml) and streptomycin $(100 \mu \mathrm{g} / \mathrm{ml})$. Sodium dodecyl sulfate (SDS) and chemiluminescence (ECL) were brought from Life Technologies (Carlsbad, California, USA). Paraformaldehyde (PFA) and lipopolysaccharide (LPS) was provided by Sigma (St. Louis, MO, USA). The HepG2-C8 cell line was kindly provided by Prof. Ah-Ng Tony Kong, Rutgers University, USA. Both RAW264.7 cells and HepG2-C8 cells were cultured at $37^{\circ} \mathrm{C}$ in a $5 \% \mathrm{CO}_{2}$ atmosphere. Primary antibodies against iNOS, COX-2, HO-1, Nrf2, Keap1 and p62 were obtained from Cell Signaling Technologies (Danvers, MA, USA), and the antibody against $\beta$-actin was obtained from Santa Cruz Technology (Dallas, Texas, USA). Luciferase assay kits were purchased from Promega (Madison, Wisconsin, USA). Lipopolysaccharide (LPS) was provided by Sigma (St. Louis, MO, USA). 7-DGD was dissolved in DMSO at a stock concentration of $100 \mathrm{mM}$ and stored at $-40^{\circ} \mathrm{C}$.

\section{LPS-induced septic shock model}

C57BL/6 mice were obtained from the Chinese University of Hong Kong, and were fed with a standard diet and libitum. Housing conditions and all in vivo experiments were approved under the regulation of the Laboratory Animal Research Committee Guidelines of Macau University of Science and Technology. For the induction of septic shock, 8-11 week-old C57BL/6 mice were randomly divided to 7-DGD or vehicle treatment groups. Mice were pretreated with or without $5 \mathrm{mg} / \mathrm{kg}$ 7-DGD at $24 \mathrm{~h}$ and $1 \mathrm{~h}$ before the mice were intraperitoneally injected with $20 \mathrm{mg} / \mathrm{kg}$ LPS. The survival of mice was recorded in the following $84 \mathrm{~h}$.

\section{Cytotoxicity assay}

RAW264.7 cells were seeded into 96-well plates for overnight and treated with 7-DGD at concentrations of $0,3.125,6.25,12.5,25,50$, and $100 \mu \mathrm{M}$ for $24 \mathrm{~h}$ before reacting with MTT $(5 \mathrm{mg} / \mathrm{mL})$ for $4 \mathrm{~h}$. The solvent $(10 \%$ SDS, $50 \% \mathrm{~N}, \mathrm{~N}$-dimethyl formamide) was added to the mixed solution in the 96-well plates to dissolve the purple precipitate. Cell viability was analyzed in each well at $570 \mathrm{~nm}$ using an OD plate reader (Infinite M200 PRO, Germany) after overnight incubation. The formula was used to calculate cell viability according to the formula, cell viability $(\%)=\mathrm{OA}_{\text {treated }} / \mathrm{OA}_{\text {control }}$.

\section{Flow cytometric analysis}

To determine the influence of 7-DGD on the cell cycle of RAW264.7 macrophages, RAW264.7 cells $\left(1 \times 10^{6} /\right.$ well $)$ were treated with 7-DGD at concentrations of $1,5,10$, and $25 \mu \mathrm{M}$ for $24 \mathrm{~h}$, and the cells were then 
collected and washed 3 times with cold PBS and fixed with $70 \%$ ethanol for $1 \mathrm{~h}$. Subsequently, the total DNA contents were stained with PBS containing propidium iodide and $100 \mu \mathrm{g} / \mathrm{ml}$ RNase I for $30 \mathrm{~min}$ at $37^{\circ} \mathrm{C}$. Finally, the cell cycle was analyzed using a FACScan flow cytometer (Becton Dickinson, San Jose, CA, USA).

\section{Luciferase reporter activity assay}

To examine the effect of 7-DGD on ARE, ARE luciferase assay was performed in HepG2-C8 cells which were stably transfected the ARE-luciferase vector. HepG2-C8 cells $\left(5 \times 10^{4} /\right.$ well $)$ were seeded in 24-well plates for $24 \mathrm{~h}$ and then co-incubated with indicated concentrations of 7-DGD or isoliquiritigenin (ILG) for another $24 \mathrm{~h}$. The activity of ARE luciferase was analyzed using the luciferase assay kit. Briefly, HepG2-C8 cells were collected and lysed by the reporter lysis buffer (50 $\mu \mathrm{l} /$ well) and centrifuged at $12,000 \mathrm{~g}$ for $10 \mathrm{~min}$, and $25 \mu \mathrm{l}$ cell lysate supernatant was used for the determination of the luciferase activity using a Sirius luminometer (Bertold Detection System GmbH, Pforzheim, Germany). The remaining cell lysates were used for BCA protein quantification. The luciferase activity was normalized by the BCA protein quantification assay. The formula used to calculate the luciferase activity is according to the following formula, relative luciferase activity $=$ (luciferase

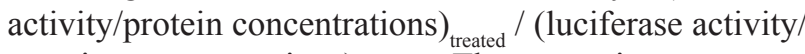
protein concentrations) $)_{\text {control }}$. The experiments were obtained from three independent experiments, and the results are presented as the mean \pm SEM.

\section{Protein extraction and western blotting}

To examine the influence of 7-DGD on iNOS and COX-2 expression, RAW264.7 cells $\left(1 \times 10^{6} /\right.$ well $)$ were pretreated with or without 7-DGD $(1,5,10,25 \mu \mathrm{M})$ for $1 \mathrm{~h}$ and then co-incubated with $100 \mathrm{ng} / \mathrm{ml}$ LPS for another $24 \mathrm{~h}$. To determine the effect of 7-DGD on HO-1, Keap1, Nrf2 and p62 expression, the cells were pretreated with or without 7-DGD for $1 \mathrm{~h}$ and then stimulated with $100 \mathrm{ng} / \mathrm{ml}$ LPS for $24 \mathrm{~h}$. After the cells were collected and lysed by $1 \times$ RIPA containing $1 \times$ protease inhibitor (Roche, USA), and the total protein concentrations were quantified using a Bio-Rad assay. To determine the effect of 7-DGD on Nrf2 nucleus translocation, the cells were incubated with 7-DGD for $24 \mathrm{~h}$, and then the cytoplasmic and nucleus extracts were prepared using NE-PER nuclear cytoplasmic extraction kit (Thermo, Pierce, USA).

After preparation, the extracts were subjected to $10 \%$ SDS-PAGE gel and were separated at $120 \mathrm{~V}$ for $90 \mathrm{~min}$ before transferring to nitrocellulose (NC) membranes for another $2 \mathrm{~h}$. Then, the NC membranes containing protein were blocked with $5 \%$ fat free milk in Tris-buffered saline with $0.1 \%$ Tween 20 (TBST). Subsequently, the membranes were incubated with primary antibodies overnight followed by incubation with HRP-conjugated secondary antibodies for 1 hour. A chemiluminescence (ECL) detection system was used to determine the antibody-bound proteins on the membrane.

\section{Quantitative real-time polymerase chain reaction}

To determine the levels of iNOS, IL- $1 \beta$, TNF- $\alpha$, HO-1, Nrf2, NQO1 and UGTIA1 mRNA expression, RAW264.7 cells $\left(1 \times 10^{6} /\right.$ well $)$ were plated in 6-well plates and pre-incubated with 7-DGD for $1 \mathrm{~h}$, followed by stimulation with LPS (100 ng/ml) for another $24 \mathrm{~h}$. Then, the total RNA of the cells was collected in $1 \mathrm{ml} /$ well Trizol (Invitrogen, Grand Island, NY). The concentration of total RNA was calculated by UV spectrophotometry at 260/280 $\mathrm{nm}$ (Nanodrop, Thermo). The expression levels of iNOS, IL-1 $\beta$, TNF- $\alpha$, HO-1, Nrf2, NQO1 and UGTIA1 mRNA were quantified by quantitative real-time polymerase chain reaction ( $\mathrm{qPCR}$ ) according to previous description.

The mouse primer sequences were listed as following:

\begin{tabular}{|c|c|}
\hline Gene & Primer sequence \\
\hline iNOS & $\begin{array}{l}\text { forward: } \\
\text { 5'-GTGGTGACAAGCACATTT } \\
\text { GG-3' } \\
\text { reverse: } \\
\text { G'-GGCTG' }\end{array}$ \\
\hline $\mathrm{HO}-1$ & $\begin{array}{l}\text { forward: 5'-CCCACCAAGTTCAAACAGC } \\
\text { TC-3' } \\
\text { reverse: 5'-AGGAAGGCGGTCTTAGCC } \\
\text { TC-3' }\end{array}$ \\
\hline Nrf2 & $\begin{array}{l}\text { forward: 5'-AGC AGG ACA TGG AGC } \\
\text { AAG TT-3' } \\
\text { reverse: 5'-TTC TTT TTC CAG CGA GGA } \\
\text { GA-3' }\end{array}$ \\
\hline NQO1 & $\begin{array}{l}\text { forward: 5'-TTCTGTGGCTTCCAGGTCT } \\
\text { T-3' } \\
\text { reverse: 5'-AGGCTGCTTGGAGCAAAAT } \\
\text { A-3' }\end{array}$ \\
\hline UGT1A1 & $\begin{array}{l}\text { forward: 5'-GTGGCCCAGTACCTGACT } \\
\text { GT-3' } \\
\text { reverse: 5'-CGATGGTCTAGTTCCGGTG } \\
\text { T-3' }\end{array}$ \\
\hline TNF- $\alpha$ : & $\begin{array}{l}\text { forward: 5'-TATGGCTCAGGGTCCAAC } \\
\text { TC-3' } \\
\text { reverse: 5'-CTCCCTTTGCAGAACTCAG } \\
\text { G-3' }\end{array}$ \\
\hline IL-1 $\beta$ : & $\begin{array}{l}\text { forward: 5'-TTGACGGACCCCAAAAGAT } \\
\text { G-3' } \\
\text { reverse: } \quad \text { 5'-AGAAGGTGCTCATGTCCT } \\
\text { CA-3' }\end{array}$ \\
\hline
\end{tabular}


$\beta$-actin forward: 5'-TGCTCGAGATGTCATGAAG G-3'

reverse: 5'-TTGCGCTCATCGTAGGCTT T-3'

\section{Immunocytochemistry}

To analyze the effect of 7-DGD on Nrf2 translocation into the nucleus, we conducted the immunocytochemistry assay. Briefly, RAW264.7 cells $\left(1 \times 10^{5} /\right.$ well $)$ were seeded on coverslips in 6-well plates and incubated overnight. The cells were then treated with different concentrations of 7-DGD for $24 \mathrm{~h}$. Cells were washed 3 times with cold PBS and fixed with 4\% PFA for $15 \mathrm{~min}$. After washed 3 times with cold PBS and permeabilized with $0.1 \%$ Triton $\mathrm{X}-100$ for $5 \mathrm{~min}$, the cells were stained with DAPI for $30 \mathrm{~min}$. Then, the cells were incubated with Nrf2 antibody overnight at $4^{\circ} \mathrm{C}$ followed by incubation with secondary antibody for $2 \mathrm{~h}$ at room temperature. After the coverslips were dried, the cells were mounted onto glass slides and analyzed by fluorescent microscopy.

\section{Statistical analyses}

The data are presented as the means \pm SEM. ANOVA with a Tukey's post-hoc test in GraphPad Prism was used to analyze the significance of the differences; ${ }^{*} p<0.05,{ }^{* *} p<0.01,{ }^{* * *} p<0.001,{ }^{*} p<0.05,{ }^{\# \#} p<0.01$, and ${ }^{\# \#} p<0.001$ were considered statistically significant.

\section{ACKNOWLEDGMENTS AND FUNDING}

This work was supported by FDCT grants from the Science and Technology Development Fund of Macao (Project code 077/2014/A2).

\section{CONFLICTS OF INTEREST}

The authors declare that they have no conflicts of interests.

\section{REFERENCES}

1. Porcheray F, Viaud S, Rimaniol AC, Léone C, Samah B, Dereuddre-Bosquet N, Dormont D, Gras G. Macrophage activation switching: an asset for the resolution of inflammation. Clin Exp Immunol. 2005; 142:481-89.

2. Laskin DL, Pendino KJ. Macrophages and inflammatory mediators in tissue injury. Annu Rev Pharmacol Toxicol. 1995; 35:655-77.

3. Humes JL, Bonney RJ, Pelus L, Dahlgren ME, Sadowski SJ, Kuehl FA Jr, Davies P. Macrophages synthesis and release prostaglandins in response to inflammatory stimuli. Nature. 1977; 269:149-51.

4. O’Neill GP, Mancini JA, Kargman S, Yergey J, Kwan MY, Falgueyret JP, Abramovitz M, Kennedy BP, Ouellet M,
Cromlish W. Overexpression of human prostaglandin G/H synthase- 1 and -2 by recombinant vaccinia virus: inhibition by nonsteroidal anti-inflammatory drugs and biosynthesis of 15-hydroxyeicosatetraenoic acid. Mol Pharmacol. 1994; 45:245-54.

5. Lee AK, Sung SH, Kim YC, Kim SG. Inhibition of lipopolysaccharide-inducible nitric oxide synthase, TNF- $\alpha$ and COX-2 expression by sauchinone effects on I-kappaBalpha phosphorylation, $\mathrm{C} / \mathrm{EBP}$ and AP-1 activation. Br J Pharmacol. 2003; 139:11-20.

6. Reuter S, Gupta SC, Chaturvedi MM, Aggarwal BB. Oxidative stress, inflammation, and cancer: how are they linked? Free Radic Biol Med. 2010; 49:1603-16.

7. Naito Y, Takagi T, Higashimura Y. Heme oxygenase-1 and anti-inflammatory M2 macrophages. Arch Biochem Biophys. 2014; 564:83-88.

8. Bryan HK, Olayanju A, Goldring CE, Park BK. The Nrf2 cell defence pathway: Keap1-dependent and -independent mechanisms of regulation. Biochem Pharmacol. 2013; 85:705-17.

9. Jaiswal AK. Nrf2 signaling in coordinated activation of antioxidant gene expression. Free Radic Biol Med. 2004; 36:1199-207.

10. Dinkova-Kostova AT, Talalay P. Direct and indirect antioxidant properties of inducers of cytoprotective proteins. Mol Nutr Food Res. 2008 (Suppl 1); 52:S128-38.

11. Su ZY, Shu L, Khor TO, Lee JH, Fuentes F, Kong AN. A perspective on dietary phytochemicals and cancer chemoprevention: oxidative stress, nrf2, and epigenomics. Top Curr Chem. 2013; 329:133-62.

12. Komatsu M, Kurokawa H, Waguri S, Taguchi K, Kobayashi A, Ichimura Y, Sou YS, Ueno I, Sakamoto A, Tong KI, Kim M, Nishito Y, Iemura S, et al. The selective autophagy substrate p62 activates the stress responsive transcription factor Nrf2 through inactivation of Keap1. Nat Cell Biol. 2010; 12:213-23.

13. Wruck CJ, Fragoulis A, Gurzynski A, Brandenburg LO, Kan YW, Chan K, Hassenpflug J, Freitag-Wolf S, Varoga D, Lippross S, Pufe T. Role of oxidative stress in rheumatoid arthritis: insights from the Nrf2-knockout mice. Ann Rheum Dis. 2011; 70:844-50.

14. Bianchini R, Nocentini G, Krausz LT, Fettucciari K, Coaccioli S, Ronchetti S, Riccardi C. Modulation of pro- and antiapoptotic molecules in double-positive (CD4+CD8+) thymocytes following dexamethasone treatment. J Pharmacol Exp Ther. 2006; 319:887-97.

15. Kim J, Cha YN, Surh YJ. A protective role of nuclear factor-erythroid 2-related factor-2 (Nrf2) in inflammatory disorders. Mutat Res. 2010a; 690:12-23.

16. Smirnova NA, Haskew-Layton RE, Basso M, Hushpulian DM, Payappilly JB, Speer RE, Ahn YH, Rakhman I, Cole PA, Pinto JT, Ratan RR, Gazaryan IG. Development of Neh2-luciferase reporter and its application for high throughput screening and real-time monitoring of Nrf2 activators. Chem Biol. 2011; 18:752-65. 
17. Piaz FD, Malafronte N, Romano A, Gallotta D, Belisario MA, Bifulco G, Gualtieri MJ, Sanogo R, Tommasi ND, Pisano C. Structural characterization of tetranortriterpenes from Pseudrocedrela kotschyi and Trichilia emetica and study of their activity towards the chaperone Hsp90. Phytochemistry. 2012; 75:78-89.

18. Santagata S, Xu YM, Wijeratne EM, Kontnik R, Rooney C, Perley CC, Kwon H, Clardy J, Kesari S, Whitesell L, Lindquist S, Gunatilaka AA. Using the heat-shock response to discover anticancer compounds that target protein homeostasis. ACS Chem Biol. 2012; 7:340-49.

19. Borges PV, Moret KH, Raghavendra NM, Maramaldo Costa TE, Monteiro AP, Carneiro AB, Pacheco P, Temerozo JR, Bou-Habib DC, das Graças Henriques M, Penido C. Protective effect of gedunin on TLR-mediated inflammation by modulation of inflammasome activation and cytokine production: evidence of a multitarget compound. Pharmacol Res. 2017; 115:65-77.

20. Murakami A, Ohigashi H. Targeting NOX, INOS and COX-2 in inflammatory cells: chemoprevention using food phytochemicals. Int J Cancer. 2007; 121:2357-63.

21. Lv H, Ren W, Zheng Y, Wang L, Lu G, Yi P, Ci X. Tenuigenin exhibits anti-inflammatory activity via inhibiting MAPK and NF- $\mathrm{KB}$ and inducing Nrf2/HO-1 signaling in macrophages. Food Funct. 2016; 7:355-63.

22. Wang R, Zhang CY, Bai LP, Pan HD, Shu LM, Kong AN, Leung EL, Liu L, Li T. Flavonoids derived from liquorice suppress murine macrophage activation by up-regulating heme oxygenase-1 independent of Nrf2 activation. Int Immunopharmacol. 2015; 28:917-24.

23. Choy EH, Panayi GS. Cytokine pathways and joint inflammation in rheumatoid arthritis. N Engl J Med. 2001; 344:907-16.
24. Abdelgaleil SA, Hashinaga F, Nakatani M. Antifungal activity of limonoids from Khaya ivorensis. Pest Manag Sci. 2005; 61:186-90.

25. Sarigaputi C, Sangpech N, Palaga T, Pudhom K. Suppression of inducible nitric oxide synthase pathway by 7-deacetylgedunin, a limonoid from Xylocarpus sp. Planta Med. 2015; 81:312-19.

26. Boutten A, Goven D, Artaud-Macari E, Boczkowski J, Bonay M. NRF2 targeting: a promising therapeutic strategy in chronic obstructive pulmonary disease. Trends Mol Med. 2011; 17:363-71.

27. Khor TO, Huang MT, Kwon KH, Chan JY, Reddy BS, Kong AN. Nrf2-deficient mice have an increased susceptibility to dextran sulfate sodium-induced colitis. Cancer Res. 2006; 66:11580-84.

28. Osburn WO, Karim B, Dolan PM, Liu G, Yamamoto M, Huso DL, Kensler TW. Increased colonic inflammatory injury and formation of aberrant crypt foci in Nrf2-deficient mice upon dextran sulfate treatment. Int J Cancer. 2007; 121:1883-91.

29. Tzima S, Victoratos P, Kranidioti K, Alexiou M, Kollias G. Myeloid heme oxygenase-1 regulates innate immunity and autoimmunity by modulating IFN-beta production. J Exp Med. 2009; 206:1167-79.

30. Kim JE, You DJ, Lee C, Ahn C, Seong JY, Hwang J. Suppression of NF-kappaB signaling by KEAP1 regulation of IKKbeta activity through autophagic degradation and inhibition of phosphorylation. Cell Signal. 2010b; 22:1645-54. 